\title{
REFLEXOS DA PANDEMIA DA COVID-19 NOS INDICADORES ECONÔMICO-FINANCEIROS DE EMPRESAS DO SETOR DE PRODUTOS DE HIGIENE E LIMPEZA LISTADAS NA B3
}

\section{COVID-19 PANDEMIC REFLECTIONS' IN THE ECONOMIC- FINANCIAL INDICATORS COMPANIES' IN THE HYGIENE AND CLEANING PRODUCTS SECTORS LISTED ON B3}

0 artigo foi aprovado e apresentado no $10^{\circ}$ Congresso UFSC de Controladoria e Finanças \& $3^{\circ}$ UFSC International Accounting Congress e $10^{\circ}$ Congresso UFSC de Iniciação Científica emContabilidade, realizado de 07/09 a 09/09 de 2020, em Florianópolis, (SC)

\section{RESUMO}

No início do ano de 2020 houve o surto da pandemia da covid-19, a qual se trata de uma infecção respiratória altamente contagiosa, recomendando-se assim, o distanciamento social e a constante higienização para reprimir a disseminação do vírus causador da doença. Frente a isso, o objetivo desta pesquisa é analisar os impactos da pandemia nos indicadores econômico-financeiro das empresas do setor de produtos de higiene e limpeza listadas na B3, considerando fabricam produtos essenciais para conter a doença através da higienização pessoal e de objetos. O estudo possui abordagem quali-quantitativa, de natureza descritiva e procedimentos documentais. Através da análise dos indicadores de liquidez, estrutura de capital e rentabilidade das empresas Bombril S.A. e da Natura Cosméticos S.A., entre os períodos do primeiro trimestre de 2019 ao terceiro período de 2020 , verificou-se que a pandemia refletiu positivamente nos relatórios financeiros de ambas as empresas, sendo perceptível o aumento considerável da receita líquida de vendas com a maximização da produção e vendas de itens essenciais neste momento, como álcool em gel, sabonetes e higienizadores. Além disso, as empresas apontam capacidade de cumprir seus compromissos, mas têm utilizado fonte de capital de terceiros para maximizar liquidez. As companhias ainda demonstram preocupações e medidas para que impactos da pandemia não afetem diretamente seus desempenhos financeiros e operacionais.

Palavras-chave: Covid-19. Indicadores econômico-financeiros. Produtos de higiene. Produtos de limpeza.

\begin{abstract}
At the beginning of 2020 there was an outbreak of the covid-19 pandemic, which is a highly contagious respiratory infection, thus recommending social distancing and constant hygiene to repress the spread of the virus that causes the illness. In view of this, the objective of this research is to analyze the pandemic impacts' on the economic-financial indicators' hygiene and cleaning products sector companies listed in B3, considering they manufacture essential products to contain the illness through personal and object hygiene. The study has a qualitative-quantitative approach, descriptive and documental procedures. Through the liquidities' analysis, capital structure and profitability indicators' Bombril SA and Natura Cosméticos S.A., between the periods of the first quarter of 2019 to the third period of 2020, it was found that the pandemic reflected positively in the financial reports of both companies, with a noticeable increase in net sales revenue with the maximization of production and sales of essential items at this time, such as alcohol gel, soaps and sanitizers. In addition, companies indicate their ability to meet their commitments, but have used outsiders' capital to maximize liquidity. The companies also demonstrate concerns and steps to pandemic's impacts do not directly affect their financial and operational performance.
\end{abstract}

Keywords: Covid-19. Economic-financial indicators. Hygiene products. Cleaning products.

\section{Laura Brandão Costa}

Doutoranda em Ciências Contábeis pela Universidade Federal de Uberlândia (UFU). Mestre em Ciências Contábeis pela Universidade Federal de Uberlândia (UFU). Graduada em Ciências Contábeis pela Universidade Federal de Uberlândia (UFU). Contato: Avenida João Naves de Ávila, 2121, Santa Mônica, Uberlândia, MG, CEP: 38.408100. E-mail: laurab_costa@hotmail.com.

\section{lasmim Fonseca Pereira}

Graduada em Ciências Contábeis pela Universidade Federal de Uberlândia (UFU) Contato: Rua Vinte, 1600, Tupã, Ituiutaba, MG, CEP: 38.304-402. E-mail: iasmim. fonseca@hotmail.com

\section{Janaína Aparecida de Lima} Graduada em Ciências Contábeis pela Universidade Federal de Uberlândia (UFU). Contato: Rua Vinte, 1600, Tupã, Ituiutaba, MG, CEP: 38.304-402. E-mail: janaina_ lima97@hotmail.com 


\section{INTRODUÇÃO}

Em março de 2020 a World Health Organization (Organização Mundial da Saúde, OMS) declarou a covid-19 como pandemia mundial (WHO, 2020). A doença é ocasionada pelo vírus SARS-CoV-2 (novo coronavírus) e trata-se de uma síndrome aguda grave, causadora de infecções respiratórias (Macedo, Ornellas \& Bomfim, 2020). Frente ao seu elevado grau de contágio, bem como o grande número de mortes decorrentes da doença em âmbito mundial, a OMS recomendou fortemente o isolamento social para reprimir a disseminação do vírus. Além disso, a propagação da doença incorreu em consequentes impactos econômicos devido às estratégias para conter a covid-19 (Mucelin \& D’Aquino, 2020).

Segundo Gama Neto (2020) é complexo estimar os impactos de uma pandemia sobre a economia, visto que não são restritos somente à questão sanitária, mas também dispõe de consequências relevantes para a política, meio ambiente e relações sociais.

Devido ao aumento de grau de incerteza causada pelo potencial pandêmico da covid-19, a economia mundial, não excluindo a brasileira, percorre por um momento de desaceleração das atividades econômicas e financeiras (Bacen, 2020). Por outro lado, Rezende, Marcelino \& Miyaji (2020) afirmam que o advento da covid-19 no Brasil, trouxe uma série de reflexos sobre os setores produtivos da economia. Para os autores, a incerteza quanto ao futuro, decorrente das circunstâncias de isolamento social, fizeram com que as pessoas repensassem a forma de consumir, gerando por consequência, inúmeros impactos nas vendas e no faturamento das empresas.

A limitação de oferta de produtos e serviços ocasionada por essa pandemia conduziu os agentes sociais e econômicos a modificarem seus comportamentos de consumo. Diante de situações que atentam contra a vida como no caso da doença, os indivíduos, principais agentes econômicos na situação atual, inclinam-se a terem comportamentos divergentes ao habituado, em que passaram a buscar maiores demandas de produtos que causam sensação de segurança frente à grave pandemia. Itens de higiene, limpeza e alimentos são exemplos de produtos que permitem a sensação de proteção à vida (Rezende, Marcelino \& Miyaji, 2020).

Diante do exposto, em âmbito nacional, em 28 de abril de 2020 foi publicado o decreto $\mathrm{n}^{\circ} 10.329$, que altera o decreto $\mathrm{n}^{\circ} 10.282$ de 20 de março de 2020 e regulamenta a Lei ${ }^{\circ}$ 13.979, de 6 de fevereiro de 2020, o qual definiu os serviços públicos e as atividades essenciais durante a pandemia no Brasil. Dentre as atividades apontadas no decreto citam-se a produção, distribuição, comercialização e entrega de produtos de saúde, higiene, limpeza, alimentos, bebidas e materiais de construção, realizadas presencialmente ou através do comércio eletrônico.

Considerando que as empresas têm percebido impactos em suas atividades de venda e no faturamento, afetando, por conseguinte seus resultados financeiros, a análise das demonstrações contábeis possibilita compreender os perfis econômico, financeiro, patrimonial e de desempenho operacional através de indicadores extraídos de seus próprios relatórios financeiros, fornecendo informações necessárias e relevantes para seus usuários (Ferrari, 2009).

Frente à contextualização exposta, considera-se que a pandemia da covid-19 provocará impactos econômicos significativos em diversos setores da economia, além de que os produtos de higiene e limpeza são considerados itens essenciais para prevenção da contaminação da doença, além de que a análise das demonstrações contábeis na tomada de decisão devem ser consideradas devido as oscilações no mercado de ações. Assim, este estudo traz a seguinte problemática de pesquisa: quais os reflexos nos indicadores econômico-financeiros das empresas dos setores de produtos de higiene e limpeza listadas na Brasil, Bolsa e Balcão (B3) diante do enfrentamento da covid-19?

Diante disso, o objetivo deste estudo visa analisar os impactos da pandemia da covid-19 nos indicadores econômico-financeiros das empresas do setor de produtos de higiene e limpeza listadas na B3, considerando que sua atividade na produção de tais itens é essencial para enfrentamento e a contenção da doença.

Tendo em vista a problemática e objetivo desta pesquisa, este estudo justifica-se na relevância da análise dos indicadores financeiros das empresas dos setores apontados, visto que se tem o pressuposto de que essas companhias podem apresentar reflexos positivos em seus demonstrativos financeiros. Dispõe-se desta hipótese dado que, considerando que uma das medidas de prevenção contra a covid-19 recomendadas pelo Ministério da Saúde (2020) é a higienização pessoal e limpeza de superfícies, a população passou a consumir esses produtos com maior frequência. Além disso, a análise das demonstrações contábeis possibilita discussões importantes das prováveis tendências econômico-financeiras, apontando para a investigação de prováveis impactos em suas operações financeiras (Ferrari, 2009), além de contribuir para a produção científica acerca deste tema.

Este estudo está organizado em cinco seções. A primeira seção é composta desta introdução, a segunda apresenta a revisão da literatura, na terceira seção encontram-se os aspectos metodológicos, a quarta aponta os resultados do estudo e na última, encontram-se as considerações finais.

\section{REVISÃO DA LITERATURA}

Esta seção apresenta os aspectos sobre os impactos da pandemia da covid-19 nos segmentos de higiene e limpeza e acerca da relevância da análise das demonstrações contábeis, correlacionando-a com o objeto deste estudo. 


\subsection{Impactos nos segmentos de produtos de limpeza e higiene pessoal no Brasil e no mundo}

A pandemia da covid-19 resultou em consequentes impactos no mercado no âmbito de consumo mundial, fazendo com que os consumidores alterassem seus hábitos devido às incertezas diante das circunstâncias atuais (Sebrae, 2020). Frente a situações que atentam contra a vida, os consumidores tendem a ter comportamentos diferentes do habituado, demandando por produtos que proporcionam o sentimento de segurança diante do problema enfrentado (Rezende, Marcelino \& Miyaji, 2020).

Frente a esse comportamento, Nielsen (2020) aponta a existência de seis etapas das atitudes do consumidor, que estão relacionadas a eventos da pandemia as quais se citam: compras proativas para a saúde; gestão de saúde reativa; preparação da despensa; preparação para a vida em distanciamento social; vida restrita e vivendo uma nova normalidade.

Diante disso, é evidente que o aumento do consumo de produtos de manutenção geral da saúde e do bem-estar e produtos essenciais para a contenção do vírus, vêm intensificando-se conforme o crescente número de casos da covid-19 em cada etapa (Nielsen, 2020). Nesse sentido, a Tabela 1 demonstra os reflexos no consumo de produtos de limpeza e higiene pessoal no Brasil e em alguns países:

Tabela 1 - Impactos no consumo de produtos de limpeza e higiene pessoal no mundo

\begin{tabular}{|c|c|}
\hline País & Reflexos no Consumo \\
\hline Brasil & $\begin{array}{c}\text { Houve variação positiva após a aparição do primeiro caso da covid-19 nas categorias de antisséptico } \\
\text { para mãos }(+623 \%) \text {, álcool }(+85 \%) \text {, limpeza geral }(+58 \%) \text { e sabão líquido }(+33 \%) \text { em relação ao período } \\
\text { anterior ao primeiro caso da doença }\end{array}$ \\
\hline Itália & Aumento de $15 \%$ na categoria de higiene pessoal \\
\hline Estados Unidos (USA) & Aumento da demanda por produtos de prevenção e efeito sobre a saúde \\
\hline Canadá & $\begin{array}{l}\text { Crescimento na categoria álcool gel }(+166 \%) \text { e produtos de limpeza }(+15 \%) \text { tiveram crescimento por } \\
\text { meio do comércio eletrônico }\end{array}$ \\
\hline Países Baixos & $\begin{array}{l}\text { Antes de uma possível crise, a população antecipou suas compras gerando um grande crescimento nas } \\
\text { vendas de sabonete }(+202 \%) \text { e lenços faciais }(+83 \%)\end{array}$ \\
\hline Coréia & $\begin{array}{l}\text { Com o alerta sobre a covid-19, as categorias que foram mais beneficiadas eram o sabonete para as mãos } \\
\qquad(+229 \%) \text { e limpadores de superficies }(+32 \%)\end{array}$ \\
\hline Singapura & O segmento de cuidado pessoal teve um aumento de $16 \%$ e a limpeza doméstica em $21 \%$ \\
\hline Vietnã & $\begin{array}{l}\text { A preocupação com o vírus aumentou em } 45 \% \text { a compra de sabonetes e } 35 \% \text { com a aquisição de lenços } \\
\text { faciais }\end{array}$ \\
\hline Colômbia & $\begin{array}{c}\text { Até o dia } 1^{\circ} \text { de março de } 2020 \text { não havia nenhum caso confirmado da doença, no entanto, houve um } \\
\text { grande aumento de consumo de sabonetes }(+35 \%) \text {, lenços faciais }(+32 \%) \text {, limpadores líquidos }(+31 \%) \text { e } \\
\text { detergentes }(+28 \%)\end{array}$ \\
\hline Chile & Após a notícia da covid-19 as vendas de álcool gel aumentaram $29 \%$ e de máscaras, $854 \%$ \\
\hline
\end{tabular}

Fonte: Elaboração própria com base em Nielsen (2020).

O estudo realizado pela Euromonitor (2020) apontou que durante o mês de abril de 2020, houve um aumento no consumo dos brasileiros por meio do e-commerce em produtos de higiene e daqueles que elevam a imunidade do organismo, os quais oferecem maior resistência ao corpo humano.

No Brasil, o preço médio do sabão aumentou em $21 \%$ logo no início da pandemia, no entanto, a Euromonitor (2020) assenta que esse número não é preocupante e que o estoque brasileiro se manteve constante nesse período. Já no México, o preço do sabão elevou-se em $117 \%$, contra $792 \%$ no valor de lenços umedecidos vendidos nos Estados Unidos.

Devido à problemática recente, observou-se um baixo nível de estudos publicados que investigassem a pandemia da covid-19 no âmbito da contabilidade, dentre artigos em anais, periódicos, dissertações e teses, até o momento, inclusive pesquisas com problemáticas relevantes acerca do consumo de produtos de limpeza e higiene pessoal. Em se tratando de uma temática relativamente nova, os reflexos causados pela pandemia serão mais perceptíveis posteriormente, analisando-se prazos maiores e permitindo assim, análises mais complexas acerca do assunto.

\subsection{Análise das demonstrações contábeis e dos indicadores econômico-financeiros}

A análise das demonstrações contábeis é definida como uma técnica que objetiva comparar e interpretar indicadores e outros elementos extraídos de relatórios financeiros das entidades, visando fornecer aos usuários uma compreensão dos perfis financeiro, econômico e patrimonial das empresas, além do desempenho operacional das suas atividades (Ferrari, 2009). 
Segundo Ribeiro (2018) as análises das demonstrações podem ser divididas entre análise financeira, a qual permite a interpretação da situação financeira de uma entidade, capacidade de solvência e grau de liquidez; e ainda a análise econômica, a qual possibilita a compreensão das variações do patrimônio e da riqueza gerada por sua movimentação.

A aplicação de indicadores para análise das demonstrações contábeis consiste no confronto entre as contas patrimoniais e de resultado, estabelecendo uma relação lógica que permita a mensuração das circunstâncias econômico-financeiras de uma entidade (Oliveira, Silva, Zuccari \& Rios, 2010). Nesse sentido, A Tabela 2 apresenta uma breve definição dos objetivos dos principais indicadores econômico-financeiros os quais são analisados posteriormente neste estudo.

Tabela 2 - Principais finalidades dos indicadores econômico-financeiros

\begin{tabular}{c|c}
\hline Indicadores & Objetivos \\
\hline Indicadores de Liquidez & Visam medir a capacidade de uma empresa cumprir com as suas obrigações \\
Indicadores de Estrutura de Capital & $\begin{array}{c}\text { Apontam o grau de comprometimento financeiro que uma organização possui diante de seus } \\
\text { fornecedores e investidores verificando a capacidade de cumprir com seus compromissos }\end{array}$ \\
Indicadores de Rentabilidade & Objetivam analisar os retornos obtidos por uma empresa \\
\hline
\end{tabular}

Fonte: Elaboração própria com base em Assaf Neto \& Lima (2014).

Diante da contextualização apresentada, ressalta-se que é possível evidenciar a situação econômico-financeira de toda e qualquer organização através da utilização dos índices financeiros e econômicos. A interpretação desses indicadores permite que os stakeholders avaliem a situação de uma organização e acompanhem o seu desempenho, fornecendo suporte para tomada de decisões futuras, além de minimizar riscos e alcançar os objetivos corporativos (Oliveira et al, 2010).

\section{ASPECTOS METODOLÓGICOS}

Considerando que o objetivo da presente pesquisa visa analisar os impactos da pandemia da covid-19 nos indicadores econômico-financeiros das empresas do setor de produtos de higiene e limpeza listadas na B3, esta se caracteriza como descritiva, pois segundo Gil (2014), especifica as características de determinada população. Além disso, compreende-se de um estudo com abordagem quali-quantitativa, definindo-se quanto aos procedimentos de coleta $\mathrm{e}$ análise dos dados como documental utilizando-se de fonte de dados secundários. Ademais, os dados foram coletados na base de dados da plataforma Economatica ${ }^{\circledR}$, considerando os indicadores econômico-financeiros de liquidez, estrutura de capital e de rentabilidade. Quanto aos procedimentos de análise de dados, foram utilizadas a estatística descritiva e o teste de média. Além disso, os resultados foram discutidos e pautados nas notas explicativas e no Relatório de Administração divulgadas nas demonstrações contábeis anuais consolidadas das empresas da amostra, analisados por meio de análise de conteúdo.

Devido à recomendação da OMS de isolamento social para que a pandemia da covid-19 fosse contida (Gayer, 2020), a população se viu em ambiente domiciliar tomando as devidas precauções. Desse modo, o consumo das famílias está nesse momento de pandemia, concentrado em bens de primeira necessidade como alimentação e saúde (Teixeira, Poltronieri Bifi, Pinto \& Bandeira, 2020). No Brasil, o Decreto ${ }^{\circ} 10.329$ (Brasil, 2020) em seu artigo $3^{\circ}$, inciso XII aponta que a "produção, distribuição, comercialização e entrega realizadas presencialmente ou por meio do comércio eletrônico, de produtos de saúde, higiene, limpeza, alimentos, bebidas e materiais de construção", são itens considerados essenciais no momento de enfrentamento à pandemia. Dessa forma, apenas os estabelecimentos que atuam com tais atividades tinham prioridade para funcionarem, no momento da execução desta pesquisa.

A população de análise desta pesquisa é composta de três companhias pertencentes aos setores de produtos de limpeza e de uso pessoal, listadas na B3. No entanto, uma empresa (Natura \&Co Holding S.A.) trata-se de uma gestora de participações societárias em sociedades que desenvolvem suas atividades principais no ramo de beleza e, portanto, não será considerada na amostra final. Diante disso, a amostra final compreende-se de duas companhias, sendo a Bombril S.A. e Natura Cosméticos S.A. Assim, a escolha para definição desta amostra justifica-se no sentido de serem itens definidos como essenciais para enfrentamento à pandemia (Gayer, 2020; Teixeira et al, 2020) e serem produzidos por tais companhias.

No que tange às variáveis a serem analisadas, são compreendidos os indicadores econômico-financeiros das empresas dos setores de produto de higiene e limpeza listadas na B3 referente às companhias citadas anteriormente abrangendo o período do $1^{\circ}$ trimestre de 2019 (1TR19) até o $3^{\circ}$ trimestre de 2020 (3TR20). A divisão cronológica definida justifica-se na possibilidade de observar-se uma tendência, verificando oscilações ou estabilidades dos indicadores econômico-financeiros em período anterior e durante a pandemia vivenciada atualmente, de maneira que tais resultados sejam investigados trimestralmente. Adiciona-se que o último trimestre de 2020 não foi considerado para análise já que tal período não se encontra encerrado até o momento desta pesquisa.

Referindo-se aos indicadores econômico-financeiros, estes foram coletados diretamente na plataforma Economati$\mathrm{ca} 囚$, considerando portanto, os mesmos itens de análise para ambas as empresas investigadas. As informações sobre os dados a serem analisados posteriormente são apresentadas na Tabela 3: 
Tabela 3 - Indicadores divulgados pela Economatica ${ }^{\circledR}$

\begin{tabular}{|c|c|}
\hline Indicadores & Função \\
\hline \multicolumn{2}{|r|}{ Indicadores de Liquidez } \\
\hline Geral & $\begin{array}{c}\text { (Ativo Circulante }+ \text { Realizável a Longo Prazo) } /(\text { Passivo Circulante }+ \text { Passivo Não } \\
\text { Circulante) }\end{array}$ \\
\hline Corrente & Ativo Circulante / Passivo Circulante \\
\hline Seca & (Ativo Circulante - Estoques) / Passivo Circulante \\
\hline Capital de giro & Ativo Circulante - Passivo Circulante \\
\hline \multicolumn{2}{|c|}{ Indicadores de Estrutura de Capital } \\
\hline Dívida total bruta & $\begin{array}{l}\text { Total empréstimos e financiamentos a Curto Prazo + Total empréstimos e finan- } \\
\text { ciamentos a Longo Prazo }\end{array}$ \\
\hline Dívida bruta/Ativo total & (Dívida Total Bruta / Ativo Total) x 100 \\
\hline Dívida bruta/Patrimônio líquido & $\begin{array}{l}\text { Dívida Total Bruta / (Patrimônio Líquido + Participação Acionistas Minoritários) } \\
\text { x } 100\end{array}$ \\
\hline Dívida bruta/EBITDA & Dívida Total Bruta / EBITDA \\
\hline Investimentos/Patrimônio líquido & $\begin{array}{c}\text { (Investimentos em subsidiárias e outros / Patrimônio Líquido + Participação } \\
\text { Acionistas Minoritários) x } 100\end{array}$ \\
\hline \multicolumn{2}{|r|}{ Indicadores de Rentabilidade } \\
\hline EBITDA & Lucro antes de juros e impostos (EBIT) + Depreciação, amortização e exaustão \\
\hline Giro do ativo & Receita Líquida Operacional / Ativo Total \\
\hline Giro do Patrimônio líquido & $\begin{array}{c}\text { Receita Líquida Operacional / (Patrimônio Líquido + Participação Acionistas } \\
\text { Minoritários) }\end{array}$ \\
\hline Margem bruta & (Lucro Bruto / Receita Líquida Operacional) x 100 \\
\hline Margem EBITDA & (EBITDA / Receita Líquida Operacional) x 100 \\
\hline ROA Rentabilidade do ativo & (Lucro Líquido + Participação Acionistas Minoritários) / Ativo Total x 100 \\
\hline ROE Rentabilidade do patrimônio líquido & $\begin{array}{c}\text { (Lucro Líquido + Participação Acionistas Minoritários) / (Patrimônio Líquido + } \\
\text { Participação Acionistas Minoritários) x } 100\end{array}$ \\
\hline ROIC Retorno sobre o capital investido & $\begin{array}{l}\text { (1-imposto de renda/100) x (Lucro antes de juros e impostos/capital investido) } \\
\text { x } 100\end{array}$ \\
\hline Capital investido & $\begin{array}{c}\text { Ativo Total - Passivo Circulante }+ \text { Total empréstimos e financiamentos a Curto } \\
\text { Prazo - Disponível e Investimentos a Curto Prazo - Aplicações Financeiras a } \\
\text { Curto Prazo }\end{array}$ \\
\hline
\end{tabular}

Fonte: Elaborado com base na Economatica ${ }^{\circledR}$ e adaptados com base em Vieira et al. (2014).

Ressalta-se que além da análise dos indicadores de liquidez, estrutura de capital e de rentabilidade, também foram investigados o conjunto das notas explicativas e o relatório de administração, ambos publicados pelas companhias, com o objetivo de verificar se as empresas mencionam informações relacionadas a covid-19, bem como analisar possíveis impactos da pandemia nos relatórios financeiros. Para tanto, foi aplicada a análise de conteúdo, que para Bardin (2011), o termo corresponde a técnicas de análise comunicativas objetivando captar procedimentos sistemáticos para consolidação de conhecimentos em relação às variáveis analisadas.

\section{ANÁLISE DOS RESULTADOS}

Na presente seção são apresentados e discutidos os resultados da pesquisa, cujos apontamentos estão segregados por indicadores em subseções. 


\subsection{Indicadores de liquidez}

Ferrari (2009) aponta que os indicadores de liquidez objetivam medir a capacidade de uma empresa quitar suas dívidas a curto e/ou longo prazos, através da aplicação de recursos no ativo. Dessa maneira, quanto maior o índice de liquidez, maior capacidade de pagar as dívidas e, consequentemente, melhor é a situação financeira. Frente a isso, os indicadores de liquidez das empresas da amostra são evidenciados na Tabela 4.

Tabela 4 - Comparação dos indicadores de liquidez das amostras

\begin{tabular}{c|c|c|c|c|c|c|c}
\hline Liquidez Geral & 1TR19 & 2TR19 & 3TR19 & 4TR19 & $\mathbf{1 T R 2 0}$ & 2TR20 & 3TR20 \\
\hline Bombril & 0,37 & 0,37 & 0,35 & 0,40 & 0,43 & 0,40 & 0,40 \\
Natura & 0,53 & 0,56 & 0,57 & 0,66 & 0,56 & 0,60 & 0,60 \\
\hline Liquidez Corrente & $\mathbf{1 T R 1 9}$ & $\mathbf{2 T R 1 9}$ & $\mathbf{3 T R 1 9}$ & $\mathbf{4 T R 1 9}$ & $\mathbf{1 T R 2 0}$ & $\mathbf{2 T R 2 0}$ & $\mathbf{3 T R 2 0}$ \\
\hline Bombril & 0,51 & 0,50 & 0,54 & 0,57 & 0,61 & 0,6 & 0,6 \\
Natura & 1,33 & 1,36 & 1,54 & 1,25 & 1,20 & 1,30 & 1,10 \\
\hline Liquidez Seca & $\mathbf{1 T R 1 9}$ & $\mathbf{2 T R 1 9}$ & $\mathbf{3 T R 1 9}$ & $\mathbf{4 T R 1 9}$ & $\mathbf{1 T R 2 0}$ & $\mathbf{2 T R 2 0}$ & $\mathbf{3 T R 2 0}$ \\
\hline Bombril & 0,36 & 0,35 & 0,37 & 0,46 & 0,47 & 0,4 & 0,4 \\
Natura & 0,95 & 0,98 & 1,10 & 1,06 & 0,85 & 1,00 & 0,8 \\
\hline Capital de Giro (em milhões R\$) & $\mathbf{1 T R 1 9}$ & $\mathbf{2 T R 1 9}$ & $\mathbf{3 T R 1 9}$ & $\mathbf{4 T R 1 9}$ & $\mathbf{1 T R 2 0}$ & $\mathbf{2 T R 2 0}$ & $\mathbf{3 T R 2 0}$ \\
\hline Bombril & $-236,55$ & $-247,76$ & $-212,15$ & $-199,84$ & $-185,06$ & $-188,16$ & $-190,18$ \\
Natura & 1332,80 & 1547,63 & 2168,00 & 1911,63 & 2327,16 & 4201,00 & 2382,00 \\
\hline
\end{tabular}

Fonte: Dados da pesquisa (2020).

A liquidez geral aponta a capacidade de uma empresa pagar as obrigações de curto e longo prazos, utilizando para tanto, recursos aplicados no ativo circulante e no realizável a longo prazo. A Bombril se manteve constante no período de um ano, com o indicador oscilando por volta de 0,4 . Por outro lado, a Natura apresentou indicadores de liquidez geral maiores do que a Bombril em todos os trimestres, apontando ainda, um leve aumento em dezembro de 2019 e encerrando o 3 TR20 em 0,60.

Desse modo, mesmo que os indicadores não sejam considerados como uma boa situação financeira, pois o ideal seria que fossem maiores do que 1 para liquidez geral, as empresas conseguem cumprir com seus compromissos, mantendo-se constantes no período durante a pandemia bem como quando comparados ao mesmo período do ano anterior.

É interessante ressaltar que a Natura pode ter apresentado maior índice de liquidez geral em dezembro de 2019 devido ao alto valor na conta caixa. Por outro lado, esse excesso poderia ter sido aplicado em estoques, por exemplo. No entanto, no relatório 1TR20, a companhia cita adotar medidas de proteção ao caixa reduzindo despesas operacionais, limitação de investimentos, congelamento de contratações e redução voluntária da remuneração dos executivos, contribuindo para a liquidez, enfatizando que tais medidas atuam como enfrentamento aos impactos da pandemia.

O indicador de liquidez corrente da Bombril em 1TR19 estava em 0,51 apresentando uma leve alta ao encerrar o 3TR20 em 0,6. Entretanto, o oposto ocorreu com a Natura, que apresentou 1TR19 com 1,33 e queda para 1,10 em 3TR20. No entanto, nota-se que a Natura tem uma maior folga se comparada com a Bombril na capacidade de quitar dívidas em curto prazo utilizando recursos aplicados no ativo circulante.

Destaca-se que a liquidez de modo geral, é um indicador que se associa ao ciclo operacional e geralmente o setor de indústria deveria manter esse índice com valor mais alto, pois a maior parte dos recursos é aplicada em uma variedade de estoques. Assim, em uma análise mais pormenorizada, considerando que a Bombril possui um ciclo operacional de 86,4 dias no 3TR20 e a Natura 224,5, esta última apresenta maior ciclo operacional, apontando, portanto, maior índice de liquidez quando comparada com a Bombril.

Com relação ao indicador de liquidez seca, nota-se que a Natura apontou índices maiores do que a Bombril em todos os trimestres, finalizando o 3TR20 em 0,8 e a Bombril em 0,4. Assim, para cada real de dívidas de curto prazo, as empresas possuem recursos aplicados no ativo, sem considerar os estoques.

Com relação ao capital de giro, a Natura no 3TR20 apontou que o período foi impactado pela extensão de termos aos consultores e revendedoras de sua marca, sendo evidenciado seu alto valor devido à proteção do seu caixa. Já a Bombril aponta que executa a antecipação de seus recebíveis através de cessão de duplicatas junto às instituições financeiras como ferramenta de capital de giro.

Com relação aos indicadores de liquidez, a Natura demonstrou aumento de tal indicador devido às linhas de financiamento adicionais, posição sólida do caixa e nenhum vencimento imediato de dívida durante a pandemia. A com- 
panhia ainda aponta esse fortalecimento devido ao congelamento de contratações e aumento de salários e viagens, redução de gastos discricionários, renegociação de alugueis e baixa da carga horária das equipes.

Já a Bombril assenta quanto à sua liquidez que durante a pandemia da covid-19 continua reduzindo seus custos e despesas, dilatando prazos de empréstimos e financiamentos e diminuindo obrigações de parcelamentos fiscais e prazo médio de pagamento. Dessa maneira, vem apresentando situação propícia para o exercício atual, dando perspectivas de investimentos.

\subsection{Indicadores de estrutura de capital}

Os indicadores de estrutura de capital, também chamados de endividamento têm a finalidade de avaliar o grau de dependência da empresa em relação aos capitais de terceiros pela medida de relação entre os capitais próprios, capitais de terceiros e capitais aplicados (Ferrari, 2009). Considerando que os indicadores de estrutura de capital demonstram a política de obtenção de recursos por uma empresa, a Tabela 5 aponta os resultados dos indicadores das empresas da amostra.

Tabela 5 - Indicadores de estrutura de capital

\begin{tabular}{|c|c|c|c|c|c|c|c|}
\hline Divida Total Bruta & $1 T R 19$ & 2TR19 & 3TR19 & 4TR19 & 1TR20 & 2TR20 & 3TR20 \\
\hline Bombril & 282,80 & 285,02 & 302,50 & 320,19 & 273,65 & 264,11 & 228,26 \\
\hline Natura & 7399,37 & 7603,72 & 8013,63 & 10786,37 & 19333,07 & 20666,00 & 20518,00 \\
\hline $\begin{array}{c}\text { Divida Bruta/Ativo Total } \\
\text { (em \%) }\end{array}$ & 1TR19 & 2TR19 & 3TR19 & 4TR19 & 1TR20 & 2TR20 & 3TR20 \\
\hline Bombril & 46,76 & 46,85 & 50,94 & 48,69 & 40,27 & 37,9 & 34,3 \\
\hline Natura & 45,98 & 45,98 & 45,47 & 50,92 & 34,49 & 33,8 & 31,9 \\
\hline $\begin{array}{c}\text { Divida Bruta/Patrimônio } \\
\text { Líquido (em \%) }\end{array}$ & 1TR19 & 2TR19 & 3TR19 & 4TR19 & 1TR20 & 2TR20 & 3TR20 \\
\hline Bombril & $-114,54$ & $-107,30$ & $-108,14$ & $-112,30$ & $-105,85$ & $-103,7$ & $-94,6$ \\
\hline Natura & 270,66 & 281,71 & 262,06 & 320,80 & 95,26 & 88,8 & 83,3 \\
\hline Divida Bruta/EBITDA & 1TR19 & 2TR19 & 3TR19 & 4TR19 & 1TR20 & 2TR20 & 3TR20 \\
\hline Bombril & 8,23 & 10,72 & 6,13 & 3,75 & 2,34 & 2,00 & 1,5 \\
\hline Natura & 3,73 & 3,45 & 3,53 & 4,37 & 9,02 & 9,1 & 6,5 \\
\hline $\begin{array}{c}\text { Investimentos/Patrimônio } \\
\text { Líquido }\end{array}$ & 1TR19 & 2TR19 & 3TR19 & 4TR19 & 1TR20 & 2TR20 & 3TR20 \\
\hline Bombril & 0 & 0 & 0 & 0 & 0 & 0 & 0 \\
\hline Natura & 0 & 0 & 0 & 0 & 0 & 0 & 0 \\
\hline
\end{tabular}

Fonte: Dados da pesquisa (2020).

Evidencia-se através da Tabela 5 que a Natura possui explicitamente uma maior dívida total bruta em todos os trimestres quando comparada com a Bombril. Com relação a este item, a Bombril teve redução do 1TR19 para o 3TR20, enquanto a Natura apontou aumento de quase três vezes no volume total da dívida bruta. Diante disso, observa-se que quando se analisa a proporção da dívida bruta pelo ativo total, a Bombril apresenta índice maior $(34,3)$ do que a Natura $(31,8)$ no 3TR20, evidenciando redução por ambas as companhias do 1TR19 para o último trimestre analisado referente ao ano de 2020. Assim, nota-se que a Bombril possui maior parcela do ativo financiada por capital de terceiros, comparando-se com a Natura.

Com relação à dívida bruta sobre o patrimônio líquido, a Bombril apresentou em todos os trimestres, índices com valores negativos, isso porque apresentou prejuízos acumulados em todos os períodos analisados. Por outro lado, a Natura reduziu de 270,7 no 1TR19 para 83,3 no 3TR20, enfatizando mais recentemente que essa parcela do ativo é financiada por capitais próprios.

A relação entre a dívida bruta e o EBITDA da Bombril apontou brusca redução de 8,2 no 1TR19 para 1,5 no 3TR20, ocorrendo o inverso com a Natura saindo de 3,73 no 1TR19 para 6,5 no 3TR20, apontando oscilações entre os períodos. Assim, a Bombril apresenta índice melhor, apontando maior capacidade de cumprir os seus compromissos. Cabe ainda ressaltar que os saldos negativos evidenciados quanto à relação da dívida bruta sobre o patrimônio líquido foram ocasionados devido à inversão do patrimônio líquido, gerando indicadores negativos.

Vale salientar ainda que nenhuma das empresas apresentou indicador de investimento sobre o patrimônio líquido, ou seja, não possui ativos de investimentos financiados por capital próprio. 
Ao se analisar o relatório financeiro do 1TR20 da Natura, imediatamente no período inicial da pandemia, nota-se que houve a consolidação dos indicadores de estrutura de capital devido ao caixa estável e aumento da liquidez. Além disso, apontou-se aumento do seu capital subscrito pelos seus acionistas minoritários visando assegurar a estrutura de capital e diminuir a alavancagem. Além disso, um financiamento foi contraído no prazo de um ano para maximizar a liquidez. Já a Bombril, no relatório de 1TR20 ressalta que gerencia os riscos de liquidez de forma que faz a captação de empréstimos que julgue necessário com base na combinação de vencimento dos seus ativos e passivos.

\subsection{Indicadores de rentabilidade}

Os indicadores de rentabilidade medem os retornos de capitais através dos lucros, bem como das receitas (Ferrari, 2009). A Tabela 6 aponta os resultados de tais índices das empresas da amostra.

Tabela 6 - Indicadores de rentabilidade

\begin{tabular}{|c|c|c|c|c|c|c|c|}
\hline Ebitda (em milhões R\$) & 1TR19 & 2TR19 & 3TR19 & 4TR19 & 1TR20 & 2TR20 & 3TR20 \\
\hline Bombril & 34,37 & 26,60 & 49,33 & 85,35 & 116,72 & 133,055 & 150,23 \\
\hline Natura & 1983,83 & 2206,88 & 2269,28 & 2468,66 & 2143,37 & 2259,00 & 3168,00 \\
\hline Giro do Ativo & 1TR19 & 2TR19 & 3TR19 & 4TR19 & 1TR20 & 2TR20 & 3TR20 \\
\hline Bombril & 1,82 & 1,83 & 1,88 & 1,61 & 1,56 & 1,50 & 1,60 \\
\hline Natura & 0,84 & 0,84 & 0,80 & 0,68 & 0,34 & 0,4 & 0,5 \\
\hline Giro do Patrimônio Líquido & 1TR19 & 2TR19 & 3TR19 & 4TR19 & 1TR20 & 2TR20 & 3TR20 \\
\hline Bombril & $-4,46$ & $-4,18$ & $-3,99$ & $-3,72$ & $-4,11$ & $-4,20$ & $-4,50$ \\
\hline Natura & 4,97 & 5,15 & 4,62 & 4,30 & 0,94 & 1,00 & 1,20 \\
\hline Margem Bruta (em \%) & 1TR19 & 2TR19 & 3TR19 & 4TR19 & 1TR20 & 2TR20 & 3TR20 \\
\hline Bombril & 42,23 & 42,43 & 42,37 & 38,79 & 37,90 & 36,3 & 35,0 \\
\hline Natura & 71,79 & 71,90 & 71,65 & 72,08 & 67,96 & 66,8 & 65,4 \\
\hline Margem EBITDA & 1TR19 & 2TR19 & 3TR19 & 4TR19 & 1TR20 & 2TR20 & 3TR20 \\
\hline Bombril & 3,12 & 2,39 & 4,42 & 8,05 & 10,99 & 10,50 & 12,10 \\
\hline Natura & 14,60 & 15,88 & 16,06 & 17,09 & 11,25 & 10,00 & 10,70 \\
\hline ROA (em \%) & 1TR19 & 2TR19 & 3TR19 & 4TR19 & 1TR20 & 2TR20 & 3TR20 \\
\hline Bombril & 13,30 & 11,16 & $-12,18$ & $-6,16$ & $-1,23$ & 2,00 & 5,80 \\
\hline Natura & 3,48 & 3,53 & 2,92 & 0,73 & $-1,22$ & $-1,90$ & $-1,30$ \\
\hline ROE (em \%) & 1TR19 & 2TR19 & 3TR19 & 4TR19 & 1TR20 & 2TR20 & 3TR20 \\
\hline Bombril & - & - & - & - & - & - & - \\
\hline Natura & 20,47 & 21,63 & 16,83 & 4,62 & $-3,37$ & $-4,90$ & $-3,30$ \\
\hline ROIC (em \%) & 1TR19 & 2TR19 & 3TR19 & 4TR19 & 1TR20 & 2TR20 & 3TR20 \\
\hline Bombril & 1,91 & 0,40 & 4,40 & 9,44 & 15,20 & 18,70 & 23,10 \\
\hline Natura & 7,24 & 7,82 & 6,83 & 7,77 & 1,05 & 0,50 & 1,20 \\
\hline $\begin{array}{c}\text { Capital Investido (em milhões } \\
\text { RS) }\end{array}$ & 1TR19 & 2TR19 & 3TR19 & 4TR19 & 1TR20 & 2TR20 & 3TR20 \\
\hline Bombril & 362,73 & 357,76 & 362,89 & 426,26 & 405,08 & 392,74 & 373,37 \\
\hline Natura & 11472,59 & 11417,75 & 12362,64 & 11481,02 & 41901,38 & 43470,00 & 44188,00 \\
\hline
\end{tabular}

Fonte: Dados da pesquisa (2020). 
A Tabela 6 aponta que com relação ao EBITDA, a Natura apresenta valor significativamente maior em todos os trimestres comparando-se com a Bombril, ressaltando que gerou número expressivo de recursos com as suas atividades operacionais.

Com relação ao giro do ativo, um indicador de rotatividade, a Bombril mostrou valores superiores em todos os trimestres saindo de 1,82 (1TR19) para 1,60 (3TR20) frente à Natura, com 0,84 (1TR19) para 0,5 (3TR20). Dessa forma, a Bombril apresenta maior velocidade com relação ao valor gerado pela receita de vendas e retornado à empresa em investimento no seu ativo, o que pode ser pautado na recolocação de itens em estoque para vendas posteriores dos produtos essenciais incentivados pela prevenção da pandemia. Diante disso, ressalta-se que para as empresas em análise, o aumento de suas vendas corrobora com os achados de Nielsen (2020) em que se aponta a alta nas vendas nas categorias de itens essenciais para enfrentamento à doença, os quais são vendidos pela Bombril também pela Natura como antisséptico para mãos, álcool e itens de limpeza geral.

Ao se analisar o giro do patrimônio líquido, percebe-se que para ambas as companhias os índices são baixos. A Bombril apresentou indicadores negativos em todos os trimestres, dado que foram ocasionados pelos saldos de prejuízos acumulados do patrimônio líquido. Por outro lado, a Natura saltou de 4,97 (1T19) para 1,20 (3TR20), indicando que as empresas estão apresentando queda nos saldos de patrimônio líquido.

Ao se analisar o percentual da margem bruta, verifica-se que a Natura apresentou no 3TR20 um número maior de margem $(65,4 \%)$ do que o valor de $35 \%$ da Bombril, apresentando quedas em ambas as companhias quando comparadas com o mesmo período do ano anterior. Com relação à margem bruta sobre o EBITDA, nota-se que as empresas mantiveram posições invertidas, sendo que a Bombril iniciou o 1TR19 com 3,12 e encerrou o 3TR20 com 12,10. Já a Natura iniciou 1TR19 com 14,60 e finalizou o 3TR20 com 10,70. Sendo assim, na margem EBITDA, a Bombril teve desempenho mais favorável do que a Natura.

Para a rentabilidade do ativo (ROA) a Bombril apresentou queda com algumas oscilações positivas e negativas, encerrando o 3TR20 com 5,80\% e a Natura em -1,30\%. Assim, esta última companhia mostrou pouca capacidade de gerar lucro com o montante de ativos que ela possui, além de ser evidenciada queda nos lucros operacionais por ambas as companhias.

Quando se analisa a rentabilidade sobre o patrimônio líquido (ROE), verifica-se que a Bombril não apresenta nenhum indicador e que a Natura apontou baixa significativa (de 20,47 no 1TR19 para -3,30 no 3TR20), ou seja, vem demonstrando pouca capacidade de gerar lucro com o capital de acionistas. Quanto ao retorno sobre o capital investido (ROIC) no 3TR20, verifica-se que a Bombril já aparece com uma porcentagem superior (23,10\%) ao da Natura (1,20\%), ou seja, a empresa possui mais capacidade de geração de lucro, considerando além do capital de acionistas, o capital de terceiros. Porém, um ponto a ser destacado é que a Natura apresenta um valor bastante relevante de capital investido no 1TR20 quando comparada à Bombril que corresponde a cerca de dez vezes menos.

Considerando os indicadores evidenciados, a Natura divulga em seu relatório de 1TR20 que a sua rentabilidade foi causada pelo aumento nas suas vendas e na alavancagem operacional. Ressalta-se que a margem EBITDA nesse trimestre foi maior quando comparado com o mesmo período do ano anterior, apesar do fechamento das lojas físicas devido à pandemia da covid-19 ocorrido no início da sua manifestação no Brasil (em fevereiro). No entanto, em março de 2020 o EBITDA apresentou aumento devido à extensão de termos de pagamento para consultoras, além da flexibilização das condições de crédito e do aumento de comissões das vendas pelo e-commerce, corroborando com o estudo de Euromonitor (2020) o qual apontou que durante o mês de abril de 2020, com a recente declaração de pandemia pela OMS, houve um aumento no consumo nesse tipo de mercado online.

Para a Bombril houve aumento de cerca de $5 \%$ no volume de vendas no 1 TR20 com relação ao mesmo período de 2019. Além disso, a receita líquida de vendas apresentou uma melhora de quase $\mathrm{R} \$ 20$ milhões no período inicial da pandemia, resultante do aumento desse volume de vendas, bem como reposicionamento de preços, inovações, melhoria na logística e nas atividades comerciais e de marketing. Cabe um destaque ao EBITDA, o qual apresentou grande crescimento, cerca de três vezes em 1TR20 quando comparado ao 1TR19. Os achados corroboram então com Rezende, Marcelino \& Miyaji (2020) que assentam que as incertezas causadas pela pandemia na economia possibilitam gerar por consequências inúmeros impactos nas vendas e no faturamento das empresas.

\subsection{Análises estatísticas dos indicadores econômico-financeiros}

Além das apresentações dos indicadores econômico-financeiros o presente trabalho buscou ainda evidenciar através da estatística descritiva e do teste de diferença de médias, a relação entre indicadores das empresas da amostra, nomeados conforme a Tabela 7:

Tabela 7 - Variáveis da pesquisa

\begin{tabular}{c|c}
\hline Sigla & Indicador \\
\hline LC & Liquidez corrente \\
CG & Capital de giro \\
CT & Participação de capital de terceiros \\
ROA & Rentabilidade do ativo \\
\hline
\end{tabular}

Fonte: Elaborado pelas autoras com base em Vieira et al. (2014). 
Vieira et al. (2014) assentam que quanto à tomada de decisão baseada em indicadores de desempenho econômico-financeiros, analistas do mercado utilizam consideram os apontados na Tabela 7 dentre outros. Para a análise no presente estudo, foram definidos os índices de LC, CG, CT e ROA por já serem divulgados pelo Economatica ${ }^{\circledR}$ e serem analisados previamente em subseções anteriores. A Tabela 8 evidencia a estatística descritiva dos indicadores apontados:

Tabela 8 - Estatística descritiva

\begin{tabular}{c|c|c|c|c}
\hline \multirow{2}{*}{ Variável } & \multicolumn{2}{|c|}{ Bombril } & \multicolumn{2}{c}{ Natura } \\
\cline { 2 - 5 } & Média & Desvio Padrão & Média & Desvio Padrão \\
\hline LC & 0,562868853 & 0,044731898 & 1,2975504 & 0,136595773 \\
CG & $-208,5285714$ & 24,88539615 & 2267,175 & 938,3938689 \\
CT & $-106,6324208$ & 6,472425312 & 200,369 & 105,7251928 \\
ROA & 1,812939267 & 9,162145735 & 0,8922086 & 2,409928892 \\
\hline
\end{tabular}

Fonte: Dados da pesquisa.

Através da Tabela 8 verifica-se que a Natura apontou maior média com relação aos indicadores de liquidez corrente, capital de giro e participação de capital de terceiros. Por outro lado, a Bombril obteve melhor desempenho com relação à rentabilidade do ativo, com o dobro do valor evidenciado pela Natura, sendo que para Vieira et al. (2014) é um indicador mais utilizado por analistas para tomada de decisões, por ser um relevante para análise econômica com relação à lucratividade de empresas.

Diante da importância do índice ROA para a interpretação das mutações do patrimônio líquido e da riqueza gerada por uma empresa (Vieira et al. 2014), foi realizado o teste de diferença de médias para o índice de retorno do ativo de ambas as empresas.

Objetivando testar a diferença da média dos indicadores ROA para a Bombril e para a Natura, foi executado o teste $\mathrm{t}$ para duas amostras (teste $\mathrm{t}$ não pareado), com as seguintes hipóteses: $\mathrm{H}_{0}$ : a média do indicador ROA para as duas empresas são iguais e $\mathrm{H}_{1}$ : a média do indicador ROA para as duas empresas são diferentes. $\mathrm{O}$ teste de diferença de médias objetivou comparar a média do índice ROA, um importante indicador econômico (Vieira et al., 2014),

Visando verificar a normalidade dos dados foi realizado o teste Shapiro-Wilk, em que ao nível de significância estabelecido em $5 \%$ a hipótese nula não foi rejeitada, apontando que a distribuição dos resíduos para cada variável ROA das empresas é normal (valor de $\mathrm{p}=0,904$ para Bombril e valor de $\mathrm{p}=0,103$ para Natura). Além disso, a condição de variâncias iguais também foi verificada ao nível de significância $\alpha=0,05$. Como valor de $p<0,05(0,006)$ há evidência de desigualdade entre as variâncias dos resíduos.

Diante disso, procedeu-se ao cálculo da estatística teste t para duas amostras independentes, considerando variâncias desiguais para investigação das hipóteses. Considerando os valores de estatística $t=-0,099$, valor de $p=0,926$, nível de significância $\alpha=0,05$ e intervalo de confiança de 95\%, a diferença das médias do índice ROA da Bombril e Natura apontaram que não são estatisticamente diferentes entre as duas empresas.

\subsection{Pandemia da covid-19 e os relatórios financeiros}

Ao se analisar os relatórios financeiros das empresas da amostra desta pesquisa, nota-se que tanto a Bombril quanto a Natura se posicionaram acerca da pandemia da covid-19 nas informações já no primeiro trimestre de 2020. A Tabela 9 apresenta os principais assuntos abordados por ambas as companhias através das notas explicativas pertencentes nos relatórios financeiros, bem como no relatório da administração e na mensagem da administração. 
Tabela 9 - Menção da covid-19 nas informações no início da pandemia pelas empresas

\begin{tabular}{|c|c|c|}
\hline Informação & Bombril & Natura \\
\hline $\begin{array}{l}\text { Aponta que a pandemia } \\
\text { da covid-19 afetou seu } \\
\text { desempenho }\end{array}$ & $\begin{array}{l}\text { Cita estar mitigando riscos e atender novas } \\
\text { necessidades para que não ocorra falta de } \\
\text { itens essenciais para prevenção e contenção } \\
\text { da disseminação da covid-19 }\end{array}$ & Sim, afirma isso claramente \\
\hline Produção de itens essenciais & $\begin{array}{c}\text { Recolocação do item álcool em gel em sua } \\
\text { linha de produtos à venda, sendo agregado ao } \\
\text { portfólio }\end{array}$ & $\begin{array}{c}\text { Otimização e reorientação da produção de } \\
\text { itens essenciais (sabonetes e higienizadores } \\
\text { de mãos) para atender às necessidades dos } \\
\text { clientes e contribuir com o fornecimento } \\
\text { desses itens básicos }\end{array}$ \\
\hline Doações de materiais & $\begin{array}{l}\text { Retomada da produção de álcool em } \\
\text { gel, doando seus primeiros lotes a seus } \\
\text { funcionários e entidades beneficentes }\end{array}$ & $\begin{array}{l}\text { Doação de itens essenciais para diversos } \\
\text { países; uso da capacidade não utilizada de } \\
\text { uma de suas marcas para produzir álcool } \\
\text { em gel e álcool com parceiros; doações } \\
\text { de higienizadores de mão, álcool 70\% e } \\
\text { sabonetes para governos, ONGs, hospitais, } \\
\text { colaboradores, motoristas de caminhões do } \\
\text { transporte, funcionários e comunidades }\end{array}$ \\
\hline $\begin{array}{l}\text { Controle e planejamento das } \\
\text { atividades }\end{array}$ & $\begin{array}{c}\text { Revisão e identificação de eventos que possam } \\
\text { impactar o consumo dos seus produtos } \\
\text { para preservar o desempenho econômico- } \\
\text { financeiro com a criação de um Comitê de } \\
\text { Riscos }\end{array}$ & $\begin{array}{l}\text { Criação de Comitê de Crise focado em } \\
\text { impactos financeiros }\end{array}$ \\
\hline $\begin{array}{l}\text { Eventos subsequentes nas } \\
\text { Demonstrações Financeiras } \\
\text { Anuais em } 2019\end{array}$ & $\begin{array}{l}\text { A administração implementou políticas e } \\
\text { ações internas para responder a situação } \\
\text { da pandemia do coronavírus - COVID } \\
\text { 19. Enfatiza que a doença poderá afetar a } \\
\text { economia mundial e que certamente irá } \\
\text { refletir nas operações da companhia. No } \\
\text { entanto, ressalta que não identificou até o } \\
\text { momento situações ou alterações relevantes } \\
\text { nas estimativas de recuperabilidade dos ativos, } \\
\text { provisão para perdas de crédito, realização } \\
\text { líquida dos estoques e dos tributos diferidos }\end{array}$ & $\begin{array}{c}\text { Não aponta qualquer informação sobre a } \\
\text { pandemia da covid-19 }\end{array}$ \\
\hline
\end{tabular}

Fonte: Elaboração própria com base nas informações da Bombril e Natura.

De acordo com a Tabela 9 é notório que as empresas se preocuparam em apontar informações sobre a pandemia da covid-19 em seus relatórios financeiros e de administração, enfatizando reflexos em seus planejamentos operacionais e impactos financeiros, bem como a preocupação com a sociedade em que estão inseridas, no que tange a doação de itens essenciais para evitar o contágio da doença.

A Natura ainda aponta em seu relatório logo no início da declaração da pandemia que apesar da doença ter afetado seu desempenho, a empresa conseguiu reorganizar suas operações em todas as marcas acelerando a produção dos seus itens essenciais para o momento, maximizando a capacidade dos produtos, reforçando a sua condição de fabricante de itens fundamentais no combate ao contágio do vírus. Produtos como higienizadores de mãos aumentaram em cinco vezes no volume de suas vendas logo no primeiro trimestre de 2020, destacando ainda que a receita líquida consolidada cresceu ocasionada pela expansão das vendas digitais, através do e-commerce em todas as suas marcas.

Com posicionamento semelhante, a Bombril aponta que no 1TR20 a companhia teve aumento de 5\% do volume vendido, crescendo em $8 \%$ a receita líquida quando comparado ao 1TR19. A empresa destaca no relatório da administração que com o advento da pandemia da covid-19, houve melhora no volume de vendas ocasionado pela retomada da produção de itens essenciais e reposicionamento de preços. Além disso, o aumento da venda e consumo destes itens reforça o exposto por Gayer (2020), em que assenta que a população diante de isolamento em ambiente domiciliar, vem tomando as devidas precauções, consumindo de maneira prioritária bens de primeira necessidade como alimentação e saúde (Teixeira, Poltronieri Bifi, Pinto \& Bandeira, 2020).

Com relação ao atendimento presencial aos consumidores, a Natura apresenta no relatório financeiro do 1TR20 que houve queda das vendas diretamente aos clientes devido à redução de revendedores presenciais, causadas pelas restrições recomendadas para conter a pandemia. Assim, com a orientação do distanciamento social as vendas online cresceram de maneira expressiva. Frente a isso, a companhia reforça que manteve as suas operações de produção, distribuição e vendas, mesmo com todas as restrições recomendadas. 
Já a Bombril apontou um plano de recuperação da lucratividade, ressaltando que mesmo antes da pandemia já havia previsto ações nas áreas de marketing, comercial, suprimentos e industrial. Destacou-se ainda que, almejando o aumento de receita, a companhia contratou novos distribuidores regionais e fortaleceu parcerias com atuais distribuidores.

Por último, com relação à data de elaboração das demonstrações financeiras consolidadas no período inicial da pandemia, a Natura expressou que a Administração não pôde prever a extensão e duração das medidas adotadas pelos governos nos países de suas operações, impossibilitando prever os impactos diretos e indiretos da pandemia nos seus resultados operacionais e financeiros. No mesmo sentido, a Bombril também não identificou impactos que fossem relevantes para suas operações naquele momento.

\section{CONSIDERAÇÕES FINAIS}

Este estudou objetivou analisar os impactos da pandemia da covid-19 nos indicadores econômico-financeiros das empresas do setor de produtos de higiene e limpeza listadas na B3, considerando que sua atividade na produção de itens essenciais para enfretamento e a contenção da doença é relevante. Dentre os principais achados quanto aos indicadores de liquidez, evidenciou-se que Natura apresentou índices superiores aos da Bombril enfatizando ainda que mantém seu caixa constante além de congelar diversas despesas e gastos discricionários.

Com relação aos indicadores de estrutura de capital, ambas as empresas vêm apresentando prejuízos em seus resultados o que gerou impactos negativos nos índices. Além disso, a Bombril se mostrou que vem utilizando mais capital de terceiros para cumprir com as suas obrigações.

Ao se investigar os indicadores de rentabilidade verificou-se que para ambas as companhias os índices foram impactados pelo aumento das vendas no período de pandemia, com recolocação de itens como álcool em gel em linha de produção para a Bombril e pelo crescente volume de produção de sabonetes e higienizadores para a Natura. Assim, ressalta-se que houve expansão por ambas as companhias na receita líquida de vendas. No entanto, no caso da Bombril houve melhora do resultado líquido, saindo de prejuízo no exercício para lucro no exercício no período analisado. Por outro lado, a Natura saiu de lucro no exercício para prejuízo, entre 1TR19 para 3TR20, decorrente de aquisição de uma marca, portanto, não é consequência de impactos financeiros resultantes da pandemia covid-19. O expressivo aumento do consumo do item álcool em gel também pode ser resultado da conscientização da população pela recomendação de autoridades governamentais quando ao seu uso para higienização das mãos seguindo orientações da OMS e do Ministério da Saúde (Brasil, 2020).

Por meio das análises das estatísticas descritivas, considerando as médias no período analisado, verificou-se que a Natura se mostrou com maiores índices quanto a liquidez corrente, capital de giro e participação de capital de terceiros. Entretanto, para o indicador de rentabilidade do ativo, um importante item a ser considerado para tomada de decisão, a Bombril apontou resultado melhor no período analisado.

Quando se analisa os relatórios financeiros e de administração das duas empresas, percebe-se que ambas se preocuparam em esclarecer claramente, para seus diversos stakeholders, a situação financeira e operacional sobre como os impactos da pandemia refletiram em seus negócios, principalmente com relação à reinserção de produtos essenciais e perante a sua atuação na sociedade, realizando doações de itens a hospitais de campanha contra a doença, corroborando com Rezende, Marcelino \& Miyaji (2020) que assentam que tais itens dão o sentimento de proteção à vida.

É válido ressaltar que o período de análise dos relatórios financeiros se torna um fator de limitação deste estudo, devido à disponibilidade de dados até o momento desta pesquisa. Outro ponto que limita outras análises é que as empresas analisadas têm estruturas bastante diferenciadas, o que dificulta uma análise mais pormenorizada. No Brasil, a pandemia ainda está em crescimento exponencial de casos até o momento de execução desta pesquisa e se prevê que adiante, as empresas componentes da amostra sofrerão posteriores reflexos em suas atividades operacionais e financeiras, cabendo então, a oportunidade de desenvolvimento de um estudo posterior.

Portanto, sugere-se para pesquisas futuras, uma análise comparativa dos indicadores econômico-financeiros de relatórios financeiros dos trimestres futuros, bem como uma análise de empresas de diferentes setores que também, provavelmente, possam estar vivenciando os impactos da pandemia da covid-19.

\section{REFERÊNCIAS}

Assaf Neto, A., \& Lima, F. G. (2014). Curso de administração financeira. Atlas.

BACEN - Banco Central do Brasil. (2020). Relatório de Inflação, 22(1). Recuperado em 30 de junho de 2020 em https://www.bcb. gov.br/content/ri/relatorioinflacao/202003/ri202003p.pdf>.

Bardin, L.(2011). Análise de conteúdo. São Paulo:Edições 70.

Brasil. Ministério da Saúde (MS). Orientações para retomada com segurança [Internet]. 2020 Recuperado em 20 de julho de 2020 em https://coronavirus.saude.gov.br/orientacoes-para-retomada-com-seguranca.

Brasil. Decreto n. 10.329 (2020, 28 de abril). Altera o Decreto ${ }^{\circ}$ 10.282, de 20 de março de 2020, que regulamenta a Lei $n^{\circ} 13.979$, de 6 de fevereiro de 2020, para definir os serviços públicos e as atividades essenciais. Brasília, DF: Presidência da República. Recuperado em 8 de julho de 2020 em http://www.planalto.gov.br/ccivil_03/_ato2019-2022/2020/decreto/D10329.htm. 
Euromonitor International (2020). Coronavírus: informações sobre preços e disponibilidade nas Américas. Recuperado em 8 de julho de 2020 em https://go.euromonitor.com/rs/805-KOK-719/images/CH20-WO-Coronavirus-Americas-Price-and-Availability-Insights-5-26-April-2020.pdf.

Ferrari, E. L. (2009). Análise de balanços ( $3^{\mathrm{a}}$ ed.). Elsevier.

Gama Neto, R. B. (2020). Impactos da covid-19 sobre a economia mundial. Boletim de Conjuntura (BOCA), 2(5), 113-127.

Gayer, E. (2020, 26 de março). OMS reforça proposta de isolamento social contra coronavírus, mas diz que é preciso fazer mais. [Comunicado de imprensa]. https://saude.estadao.com.br/noticias/geral,oms-reforca-proposta-de-isolamento-social-contra-coronavirus-mas-diz-que-e-preciso-fazer-mais, 70003249476.

Gil, A. C. (2014). Métodos e técnicas de pesquisa social. (6 $6^{\mathrm{a}}$ ed.). Atlas.

Ministério da Saúde. (2020, 03 de julho). Sobre a Doença. [Web Site]. https://coronavirus.saude.gov.br/index.php/sobre-a-doenca

Macedo, Y. M., Ornellas, J. L., \& Bomfim, H. F. (2020). Covid-19 no Brasil: o que se espera para população subalternizada?. Revista Encantar-Educação, Cultura e Sociedade, 2, 01-10.

Mucelin, G.; D’Aquino, L. S. (2020). O papel do direito do consumidor para o bem-estar da população brasileira e o enfrentamento à pandemia de Covid-19. Revista de Direito do Consumidor, 129.

Nielsen, Company. Como o brasileiro se prepara para vida restritiva imposta pela covid-19. [Web Site]. Recuperado em 08 de julho de $2020 \mathrm{em}$ https://www.nielsen.com/br/pt/insights/article/2020/como-o-brasileiro-se-prepara-para-vida-restritiva-imposta-pela-covid-19/.

Oliveira, A. A. D., Silva, A. R. D., Zuccari, S. M. D. P., \& Rios, R. P. (2010). A análise das Demonstrações Contábeis e sua importância para evidenciar a situação econômica e financeira das organizações. Revista Eletrônica: Gestão e Negócios, 1(1), 1.

Rezende, A. A., Marcelino, J. A., \& Miyaji, M. (2020). A reinvenção das vendas: as estratégias das empresas brasileiras para gerar receitas na pandemia de covid-19. Boletim de Conjuntura (BOCA), 2(6), 53-69.

Ribeiro, O. M. (2018). Estrutura e análise de balanços. (12ª ed.) atual. Saraiva Educação.

SEBRAE. (2020). Estudo Mostra Comportamento do consumidor diante da pandemia. https://m.sebrae.com.br/sites/PortalSebrae/ artigos/estudo-mostra-novo-comportamento-do-consumidor-diante-da-pandemia,9388ad41eab21710VgnVCM1000004c00210aRCRD.

Teixeira, A. P.; Poltronieri, C. C.; Bifi, C. R.; Pinto, M. J. T.; Bandeira, R. Covid-19 trará alta complexidade para os balanços, já no $1^{\circ}$ trimestre de 2020. Revista CRC SP, 20(5).

Vieira, E. M. M.; Santos, A. A.; Lagioia, U. C. T.; Vieira, G. F.; Santos, J. F. S. (2014). Melhores grupos de índices e demonstrações contábeis para análise da situação econômico-financeira das empresas na percepção de analistas do mercado de capitais. Contabilidade, Gestão e Governança, 17(3).

World Health Organization - WHO. (2020, 11 de março). Breaking. [Comunicado de imprensa]. https://twitter.com/WHO/status/1237777021742338049. 